\title{
Syntactic Priming Effects and their Underlying Mechanisms in Language Production and Comprehension
}

\author{
Reza Raissi \\ Department of Language Teaching and Translation, Varamin-Pishva Branch, Islamic Azad University, Varamin, Iran \\ Neda Hedayat \\ Department of Language Teaching and Translation, Varamin-Pishva Branch, Islamic Azad University, Varamin, Iran \\ Fakhereh Kazemirad \\ Department of Language Teaching and Translation, Varamin-Pishva Branch, Islamic Azad University, Varamin, Iran
}

\begin{abstract}
Exposure to a syntactic structure influences the way we process a similar syntactic structure in language production and comprehension in what has been called 'syntactic priming'. Syntactic priming is a robust phenomenon which can be observed in spoken and written production, with a range of syntactic constructions in laboratory tasks and naturally occurring samples of speech, in many languages, and also across languages within the same speaker. It has been used as a vehicle for exploring language production, language comprehension, and the relationship between them. Research in syntactic priming has made it the dominant means of investigating the processes involved in language production and comprehension. Some researchers propose that there are distinct mechanisms underlying the production and comprehension of syntactic structures; however, other researchers suggest that the same mechanisms underlie syntactic priming in production and comprehension. Thus, the mechanisms underlying syntactic priming effects in production and comprehension are still under debate. Moreover, although a fairly large body of research has addressed syntactic priming in production or in comprehension, there are few studies that consider and compare priming effects in both of these modalities. Therefore, the current study reviews the literature on syntactic priming in production and contrasts these findings to those in comprehension. It also provides an overview of syntactic priming effects and mechanisms underlying these effects in both production and comprehension.
\end{abstract}

Index Terms - language production, language comprehension, syntactic priming, syntactic priming effects

\section{INTRODUCTION}

Determining what occurs when a person is processing a second language has always been a difficult issue in language research (Ameri-Golestan \& Nezakat-Alhossaini, 2012). Syntactic priming as an effective method for studying the syntactic representation has been employed to deal with such issues since 1980s (Ameri-Golestan \& Nezakat-Alhossaini, 2012; Bock, 1986; Pickering \& Ferreira, 2008). It has been considered as one of many kinds of priming which are observed in language processing and cognition (Weber, Christiansen, Indefrey, \& Hagoort, 2019). This means that priming effects in language processing can also be noticed in the repetition of particular word forms and semantic information (Weber et al., 2019). "Experimental research shows that priming occurs across a variety of structures and languages, in both written and oral modalities, in comprehension and production, and among child and adult first-language (L1) and second-language (L2) speakers" (Jackson, 2017, p. 2). It may also occur in natural discourse, as proved by first and second language corpus analyses. Jackson (2017) asserts that the connection between priming and learning has some implications for second language acquisition research, because the study of how and when priming occurs in second language production can provide critical insight into the underlying mechanisms that help second language acquisition and use. Considering participants' sensitivity to particular syntactic constructions, syntactic priming can be used as a tool to investigate syntactic processing and to reflect the facilitation of syntactic processing through the repetition of syntactic structures (Weber et al., 2019). Similarly, Ledoux, Traxler, and Swaab (2007, p. 135) state that "syntactic priming occurs when processing one stimulus facilitates processing of a subsequent stimulus". In other words, it is regarded as the facilitation of processing which occurs when a sentence has the same syntactic structure as a proceeding sentence (Ledoux et al., 2007). Branigan (2007, cited in Biria \& Golestan, 2013) argues that facilitation is useful for understanding the nature of syntactic representation. McDonough and Mackey (2008) explain that speakers have the tendency to produce a particular structure which they have encountered in their recent discourse. Ameri-Golestan and Nezakat-Alhossaini (2012) refer to syntactic priming as both a method and a mechanism. As a method, it addresses theoretical questions in linguistics and psycholinguistics, and as a mechanism it deals with the mechanisms of learning which are relevant to first and second language acquisition and production. 
Three main mechanisms have been identified for explaining the potential processes behind syntactic priming in language comprehension and production: residual activation, implicit learning of syntactic structures, and a dual mechanism (Tooley \& Traxler, 2010). Residual activation involves short-term activation, implicit learning involves long-term activation of syntactic structure, and a dual mechanism involves both of the previous concepts (Flanders, 2015; Tooley \& Traxler, 2010). In addition to providing an overview of syntactic priming and its effects in both production and comprehension of language, the present study will review in more detail these mechanistic accounts of syntactic priming effects, and how well they can explain the patterns of results observed in language comprehension and production.

\section{RESEARCH DEVELOPMENT}

Syntactic or structural priming was first experimentally demonstrated by Levelt and Kelter (1982) who worked on structural repetition (Pickering \& Ferreira, 2008). This was followed up by Bock's (1986) study in which English native speakers were influenced by the syntactic structure of an unrelated prime sentence, prior to attending to a picture and they showed the tendency to use the structure of the prime when describing the picture (Husain \& Yadav, 2020). After the discovery of syntactic priming, numerous studies have been done across a wide variety of populations and syntactic priming has been the focus of studies with children, aphasiacs, amnesiacs, bilinguals, and second and foreign language learners (Ameri-Golestan \& Nezakat-Alhossaini, 2012; Biria \& Golestan, 2013; Pickering \& Ferreira, 2008). In fact, one implication of syntactic priming is that it can tell us about how various populations represent and process language (Pickering \& Ferreira, 2008). In this regard, different aspects of language users have been studied, in terms of representation, comprehension, and production. (Ameri-Golestan \& Nezakat-Alhossaini, 2012). Syntactic priming has also been investigated in a variety of contexts and languages, using various methods. Evidence for priming has been found both in naturalistic and experimental contexts (Wolleb, 2015). Priming has also been investigated in the context of reading comprehension, listening comprehension, written production, and spoken production (Zawawi, 2017). The earliest studies in the 1980s mostly focused on native speakers of English and aimed to understand the role of priming in first language processing. Afterward, syntactic priming was investigated in the first language production of languages other than English (Zawawi, 2017). However, syntactic priming research did not remain an L1-only territory and a growing body of syntactic priming research began to investigate the second language acquisition of English from a pedagogical perspective. Subsequently, priming research gradually started to look at second languages other than English, and cross-linguistic priming in the production of bilingual speakers (Zawawi, 2017). Syntactic priming has been studied by applying experimental methods, including: a) picture description paradigm whereby the participants are asked to repeat a prime sentence and describe a visual prompt in their own words, b) sentence completion in which participants are provided with fragments of sentences as the primes to create a bias towards the production of a construction, c) sentence recall paradigm under which the participants are presented with a prime sentence that is followed by a distraction task in order to minimize the likelihood that the participants will remember the prime and they are then encouraged to recall the original prime sentence (Zawawi, 2017). In fact, the aim of this experimental method is to find out whether the participants change the original structure of the prime sentence in their recalled target sentence.

\section{SYNTACTIC PRIMING}

Syntactic priming which is sometimes called structural priming or syntactic persistence is a heavily investigated phenomenon in sentence production and comprehension (Ferreira, 2009). According to Biria and Golestan (2013, p. 13), "Syntactic priming refers to a tendency to produce or repeat a recently produced or heard structure (Bock, 1986) - that is, the phenomenon by which processing of an utterance is facilitated by processing of another one which shares the same underlying syntactic structure". In other words, "syntactic priming occurs when processing of a target sentence is facilitated following processing of a prime sentence that has the same syntactic structure" (Tooley \& Traxler, 2010, p. 925). In this regard, when speakers comprehend or produce a sentence with a particular syntactic structure, they will be more likely to use that structure again (Ferreira, 2009). For example, after a speaker hears a prepositional dative structure like 'The doctor gave the hat to the sailor', the speaker is more likely to use another prepositional dative rather than a double-object structure like 'The ballerina showed the boxer the cake' (Ferreira, 2009). Ferreira (2009) also states that syntactic priming considers the repetition of the syntactic structures of sentences. He maintains that syntactic structures' properties including aspects of meaning, sound, or words either do not affect priming or they affect priming independent of syntactic repetition. Further, Ferreira (2009) refers to the three different views of syntactic priming: The first view is related to implicit learning which indicates that the comprehension and production of particular structures strengthen the knowledge of those structures and result in repetition. This view also regards priming as notably longlived and independent of explicit memory. Based on the second view, priming reflects recent shorter-term activation of knowledge structures and can be short-lived when meaningful words are repeated from prime to target sentences. In the third view, priming is sensitive to conversational variables and coordinates knowledge structures among interlocutors to promote communicative success. Tooley and Traxler (2018) refer to the syntactic priming effects and argue that processing and representational systems which generate syntactic priming effects during language comprehension and language production are an active area of inquiry. They continue that "some accounts attribute syntactic priming effects 
to short-lived enhancement of activity in memory systems that connect abstract word-level representations to syntactic structure representations. Other accounts attribute syntactic priming effects to learning mechanisms that may underlie long-lived changes in patterns of production" (Tooley \& Traxler, 2018, p. 59).

\section{Syntactic PRiming in LANGUage Production And COMPREHENSION}

Syntactic priming was first studied in language production and began with Bock's (1986) classic study in which participants were asked to repeat some sentences and describe simple pictures (Tooley \& Traxler, 2010; Tooley \& Traxler, 2018). When they repeated a prime sentence with a particular syntactic structure, they were more likely to describe a subsequent picture using that structure (Tooley \& Traxler, 2010; Tooley \& Traxler, 2018). For example, if they had just repeated a sentence containing a prepositional object, they would be more likely to describe a subsequent picture using a prepositional object structure. In a similar fashion, the results of Bock's study suggest that syntactic structures can be primed to how particular words or word meanings are primed in semantic priming, which support the notion that abstract structural representations are stored for the syntactic structures that we use (Tooley \& Traxler, 2010). Importantly, since these results were obtained when none of the content words were the same between the prime and target sentences, this type of priming does not rely on any concrete lexical information, and is thus regarded to reflect priming of abstract syntactic structure (Tooley \& Traxler, 2018). However, subsequent research has revealed that lexical overlap between the prime and target increases the magnitude of the syntactic priming effect and this increase has been termed the 'lexical boost'. Pickering and Ferreira (2008) have also reviewed several studies which used syntactic priming for providing evidence for autonomous syntax. They explain that sentence production depends largely on abstract syntactic structures which can be defined in terms of parts of speech and phrasal constituents. In this regard, they claim that this abstract syntactic structure has a great impact on syntactic priming (Biria \& Ameri-Golestan, 2010). Although syntactic priming is robust in language production, it has also been observed in many different studies of language comprehension (Tooley \& Traxler, 2018). In fact, many complementary studies on language comprehension have emerged in the last decade (Tooley \& Traxler, 2018), and indicated that comprehending a sentence with a particular syntactic structure can ease the process of comprehending a subsequent sentence with the same syntactic structure (Tooley \& Traxler, 2010). Ledoux et al. (2007) claim that language comprehension includes the activation of stored representations of various types of knowledge. The nature of these representations, the types of information represented, and also the way in which incoming information is integrated into these representations have been very important in research on language processing (Ameri-Golestan \& Nezakat-Alhossaini, 2012; Ledoux et al., 2007). Ledoux et al. (2007) maintain that one way of addressing this issue is through syntactic priming which can provide evidence regarding the representation of and access to linguistic knowledge, in that it can demonstrate some elements of representation which are shared between the prime and target stimuli. They explain that lexical overlap is crucial to priming in comprehension, because the kind of priming observed in comprehension is semantic rather than syntactic. Ziegler and Snedeker (2019) argue that syntactic priming in comprehension is more variable than in production and it may occur with or without lexical overlap.

\section{Syntactic Priming EfFects in Language Production And Comprehension}

Syntactic priming effects have been investigated across modalities, both in production and comprehension (OltraMassuet, Sharpe, Neophytou \& Marantz, 2017). According to Oltra-Massuet, et al. (2017, p. 3), "there is consensus that syntactic priming effects in production occur without lexical boost, so that when there is lexical repetition in production, priming effects are boosted or enhanced, but this is not required to find priming effects". Mahowald, James, Futrell, and Gibson (2016) conducted a meta-analysis of syntactic priming effects in language production and found abstract syntactic priming effects to be persistent and long-lived and the lexical boost to be comparatively short-lived. However, syntactic priming effects in language comprehension depend more on lexical repetition across both prime and target sentences (Tooley \& Traxler, 2010). According to Tooley and Traxler (2010), studies indicate that syntactic priming effects associated with comprehension of a syntactic structure can be readily noticed when there are both structural and lexical overlap between primes and targets. They consider this in contrast to syntactic priming effects in language production which are easily detectable with no lexical overlap but are larger with lexical overlap between primes and targets. Traxler, Tooley, and Pickering (2014) studied the effects of a prime sentence on the processing of a target sentence in two eye-tracking experiments that were designed to determine the degree to which lexical overlap between prime and target sentences produced larger effects. The results showed that priming effects during online comprehension were larger when a verb was repeated across both the prime and target sentences. Ziegler and Snedeker (2019) argue that syntactic priming effects in language production standardly occur in the absence of lexical overlap, whereas syntactic priming effects in language comprehension frequently occur when the verb repeats from prime sentence to target sentence. To understand how syntactic priming manifest itself differently in language production and comprehension, the order in which relevant representations are activated in these processes must be considered. "In production, we start from a speech plan and generate structures and words. Comprehension involves the same representations but with the opposite starting point - we begin with sounds, find words, and construct structures, resulting in an interpretation" (Ziegler \& Snedeker, 2019, p. 367). Although the message is typically not known to the 
comprehenders, the producers will often know the message that they wish to convey and also the structure they are encoding. Therefore, the flow of information through the system, and the role of each representation is likely to be different during comprehension and production (Ziegler \& Snedeker, 2019). "It is reasonable to suppose that the message is a constant and enduring part of production and that abstract syntactic and semantic features of the message will be encoded independent of lexical choices to the degree that this is possible" (Ziegler \& Snedeker, 2019, p. 367). As a result, models of production normally involve the creation of syntactic structure prior to or in parallel with lexical choice. In contrast, theories of language comprehension are based on the observation that phonological information is converted into lexical information, with words which play a primary role in how higher-level syntactic structures are constructed or reconstructed (Ziegler \& Snedeker, 2019). Based on the logical dominance of lexical information, many theorists propose that language comprehension can proceed even without the construction of abstract syntactic representations. Thus, this difference in the logical problem of language comprehension and production implies that syntactic priming might be completely different in these two processes. Specifically, it is expected to see more consistent and robust abstract syntactic priming in language production and more lexicalized priming in language comprehension (Ziegler \& Snedeker, 2019).

\section{Mechanisms for Syntactic Priming Effects in Language Production and Comprehension}

Syntactic priming effects can be found in language production and in language comprehension (Weber et al., 2019). There are three most likely mechanisms for syntactic priming effects in both production and comprehension: a residual activation account, an implicit learning account, and a dual mechanism account (Tooley \& Traxler, 2010). Researchers suggest that syntactic priming effects may be caused by a residual activation mechanism which is short-term, meaning that the effect of a prime on a target will decrease or be eliminated when there are structurally unrelated sentences between prime and target sentence (Tooley \& Traxler, 2018). However, some experimental evidence indicates that priming effects in language production persist across several intervening sentences with no meaningful decrease in magnitude (Bock \& Griffin, 2000; cited in Tooley \& Traxler, 2018). "The residual activation account (Pickering \& Branigan, 1998), link syntactic priming to the activation of syntactic frames that are tied to lexical representations" (Weber et al., 2019, p. 202). This shows that syntactic processing is lexically guided; therefore, verb repetition will boost syntactic priming effects. However, syntactic priming can also be found with novel verbs, indicating that it has some lexically independent components. Weber et al. (2019, p. 202) argue that "even if there is lexically independent syntactic processing in a language, syntactic priming linked to verb repetition might be helpful during language acquisition because lexical repetition might provide an additional boost to the mapping process between form and meaning". Pickering and Branigan (1998, cited in Flanders, 2015) explain that the production of a particular syntactic structure may cause an activation for that specific structure's combinatorial node and this process will last for a short period of time during which the structure has a higher chance of being used. They maintain that when sentences contain a repetition of an individual lemma (verb), syntactic priming effects will increase (Flanders, 2015). According to Tooley and Traxler (2018),

Residual activation for recently processed words and their linked structural representations make a particular structure more likely to be used in subsequent utterances. When the prime and target do not share a content word, residual activation of the structural representation of the prime alone produces priming for abstract structure. When the two sentences do share a content word, residual activation for both the representation of the word and its linked structural representation yield structural priming that is then greater in magnitude than when the residual activation only occurred for the structural representation. More residual activation produces larger priming effects, under this account. (P. 60)

Another mechanism explaining priming effects is implicit learning which includes long-term activation. Based on this account, priming effects are caused by long-term implicit learning, rather than short-term activation (Bock \& Griffin, 2000; Chang, Dell, \& Bock, 2006; cited in Flanders, 2015). Implicit learning occurs when repeated exposure to a specific structure or sequence changes the strengths of connections between the elements of that structure or sequence (Seger, 1994; cited in Tooley \& Traxler, 2018). Bock and Griffin (2000; cited in Dell \& Jacobs, 2016) argue that syntactic priming is not only a temporary change to the system which its influence would rapidly fade, but instead it is a form of implicit learning and its effect persists undiminished over at least ten unrelated sentences. "The nature of implicit learning for syntactic structure is suggested to be error-based, in that a mismatch between predicted and processed structure yields greater learning through greater adjustments of weightings in the representational system" (Tooley \& Traxler, 2018, p. 60). Weber et al. (2019) assert that the implicit learning theory of structural priming has been considered as a purely structural account which is independent of lexical representations. They also explain that "During learning, syntactic priming can be interpreted as an indication of when the processing system has accommodated novel structures, because the priming effect shows that the novel grammatical regularity must have a mental representation" (Weber et al., 2019, p. 201). The repetition of syntactic structures can be helpful in the mapping of meaning onto form through reducing the error signal generated when the linguistic input does not match the expected syntactic structure. Therefore, syntactic priming effects might be strong during language learning. In this regard, there is another prediction known as the inverse preference effect based on which priming effects should be stronger for infrequent structures, in that these structures benefit most from repetition and an unexpected structure might lead to a 
larger error signal (Weber et al., 2019). In both language comprehension and production, studies have indicated that syntactic priming is sensitive to expectation modulations, including the frequency of occurrence of a specific structure. This is in line with error-based implicit learning accounts and also with the inverse preference effect. Unexpected information actually leads to a larger prediction error and, thus, a larger learning signal (Weber et al., 2019).

A further kind of mechanism that explains priming effects is a dual mechanism account which provides explanations for the pattern of syntactic priming effects and also for the differences between priming in comprehension and production (Flanders, 2015; Tooley \& Traxler, 2010). Traxler et al. (2014) argue that the correct account of syntactic priming should accommodate both comprehension and production phenomena, because neither residual activation nor implicit learning appears compatible with the full range of observed priming effects. This means that more than one mechanism contributes to the observed outcomes; hence, a number of theorists have advocated a dual-mechanism account (Traxler et al., 2014; Tooley \& Traxler, 2018). According to the dual mechanism account, lexically dependent syntactic priming effects are caused by a short-term mechanism, whereas lexically independent syntactic priming effects may be caused by a more long-lived implicit learning mechanism (Tooley \& Traxler, 2010; Tooley \& Traxler, 2018). In their study, Hartsuiker and Pickering (2008; cited in Flanders, 2015) found that lexically dependent syntactic priming effects lasted for shorter periods of time in language production, while lexically independent syntactic priming effects seemed to last longer. Therefore, different durations which have been observed for lexically dependent and independent syntactic priming effects indicate that these priming effects may be driven by two underlying mechanisms which are involved in different aspects of priming (Tooley \& Traxler, 2010). In this regard, in a dual mechanism account, lexically dependent priming effects would be explained by a short-lived mechanism which is possibly a residual activation, and lexically independent syntactic priming effects would be explained by an implicit learning mechanism (Tooley \& Traxler, 2010). Arai, Gompel, and Scheepers (2007; cited in Tooley \& Traxler, 2010) explain that observable syntactic priming effects in language comprehension are lexically dependent, which means that they are evident in cases when there is lexical overlap between the primes and targets. However, both lexically dependent and independent syntactic priming effects have been observed in language production studies (Bock 1986; Pickering \& Branigan 1998; cited in Tooley \& Traxler, 2010). If lexically dependent and lexically independent syntactic priming effects are caused by different mechanisms, and only lexically dependent effects occur in language comprehension, then this would suggest that the mechanism which produces lexically independent syntactic priming effects in language production does not manifest itself in language comprehension processes (Tooley \&Traxler, 2010).

\section{CONCLUSION}

"Research has extensively shown that exposure to a syntactic structure influences to different degrees the way we subsequently process a similar structure in comprehension and production in what has been called syntactic priming, structural priming, or structural persistence" (Oltra-Massuet, Sharpe, Neophytou, \& Marantz, 2017, p. 1). In fact, experiencing a syntactic structure affects how we process subsequent instances of that structure. Syntactic priming effects can be observed in both language production and comprehension and there are no reliable differences in how priming effects manifest across each modality. Moreover, syntactic priming effects in language production are larger with lexical overlap than without it and this is also true for these effects in language comprehension. Some researchers propose that there are distinct mechanisms underlying the production and comprehension of syntactic structures; however, other researchers suggest that the same core mechanisms produce syntactic priming effects in these two modalities: a residual activation account, an implicit learning account, and a dual mechanism account. Since neither residual activation nor implicit learning appears compatible with the full range of observed priming effects in both production and comprehension, a dual mechanism which involves both of the previous accounts has been advocated. To sum up, although syntactic priming is a well-established phenomenon, the mechanisms underlying this priming effect are still under debate and more direct comparisons between production and comprehension are suggested to help clarify the extent to which mechanisms common to both modalities contribute to syntactic priming effects.

\section{REFERENCES}

[1] Ameri-Golestan, A. \& Nezakat-Alhossaini, M. (2012). The Application of syntactic priming in second language research. Journal of Language Teaching and Research, 3(5), 898-903. doi:10.4304/jltr.3.5.898-903.

[2] Arai, M., van Gompel, R. P. G. \& Scheepers, Ch. (2007). Priming ditransitive structures in comprehension. Cognitive Psychology, 54 (3). 218-250. doi: 10.1016/j.cogpsych.2006.07.001.

[3] Biria, R. \& Ameri-Golestan, A. (2010). The impact of syntactic priming on English language learners' production: A transfer study of indirect questions/ requests. Journal of Language Teaching and Research, 1 (5), 583-590. doi:10.4304/jltr.1.5.583-590.

[4] Biria, R. \& Golestan, A. A. (2013). Syntactic priming effects on EFL learners' production and retention of indirect questions. International Journal of Research in ELT, 1(1). 13-23.

[5] Bock, J. K. (1986). Syntactic Persistence in Language Production. Cognitive Psychology, 18, 355-387. doi: 10.1016/00100285(86)90004-6

[6] Bock, K. \& Griffin, Z. M. (2000). The persistence of structural priming: Transient activation or implicit learning. J Exp Psychol Gen. 129 (2), 177 - 192. doi:10.1037//0096-3445.129.2.177.

[7] Branigan, H. (2007). Syntactic Priming. Language and Linguistics Compass, 1, 1-16. doi: 10.1111/j.1749-818X.2006.00001. 
[8] Chang, F., Dell, G. S., \& Bock, K. (2006). Becoming syntactic. Psychological Review, 113(2), 234-272. doi:10.1037//0033295X.113.2.234.

[9] Dell, G. S. \& Jacobs, C. L. (2016). Successful speaking: Cognitive mechanisms of adaptation in language production. In G. Hickok \& S. L. Small (Eds.), Neurobiology of Language, (pp. 209-219). Elsevier.

[10] Ferreira, V. S. (2009). Sentence production, Encyclopedia of Neuroscience, 687-693. doi:10.1016/B978-008045046-9.01885-4.

[11] Flanders, D. V. (2015). Structural priming in sentence production. University of Michigan. Retrieved 04, 07, 2020, from: https://deepblue.lib.umich.edu/bitstream/handle/2027.42/112085/dvflan.pdf?sequence=1\&isAllowed=y.

[12] Hartsuiker, R. J. \& Pickering, M. J. (2008). Language integration in bilingual sentence production. Acta Psychologica, 128, 479-489. doi: 10.1016/j.actpsy.2007.08.005.

[13] Husain, S. \& Yadav, H. (2020). Target complexity modulates syntactic priming during comprehension. Frontiers in Psychology, 11(454). doi: 10.3389/fpsyg.2020.00454.

[14] Jackson, C. N. (2017). Second language structural priming: A critical review and directions for future research. Second Language Research, 1-14. doi: 10.1177/0267658317746207.

[15] Ledoux, K., Traxler, M. J., \& Swaab, T. Y. (2007). Syntactic priming in comprehension: evidence from event-related potentials. Psychol Sci. 18(2), 135-143. doi:10.1111/j.1467-9280.2007.01863.x.

[16] Mahowald, K., James, A., Futrell, R. \& Gibson, E. (2016). A meta-analysis of syntactic priming in language production. Journal of Memory and Language, 91, 5-27. doi: 10.1016/j.jml.2016.03.009.

[17] McDonough, K. \& A. Mackey. (2008). Syntactic priming and ESL question development. Studies in Second Language Acquisition, 30(1), 31-47.

[18] Oltra-Massuet, I., Sharpe, V., Neophytou, K. \& Marantz, A. (2017). Syntactic priming as a test of argument structure: A selfpaced reading experiment. Frontiers in Psychology, 8 (1311). doi: 10.3389/fpsyg.2017.01311.

[19] Pickering, M. J. \& Branigan, H. P. (1998). The representation of verbs: Evidence from syntactic priming in language production. J. Mem. Lang, 39, 633-651. doi:10.1006/jmla.1998.2592.

[20] Pickering, M. J. \& Ferreira, V. S. (2008). Structural priming: A critical review. Psychol Bull, 134(3), 427-459. doi: 10.1037/0033-2909.134.3.427.

[21] Seger, C. A. (1994). Implicit learning. Psychological Bulletin, 115 (2), 163-196. doi.org/10.1037/0033-2909.115.2.163.

[22] Tooley, K. M. \& Traxler, M. J. (2018). Implicit learning of structure occurs in parallel with lexically-mediated syntactic priming effects in sentence comprehension. Journal of Memory and Language, 98, 59-76. doi: 10.1016/j.jml.2017.09.004.

[23] Tooley, K. M., \& Traxler, M. J. (2010). Syntactic priming effects in comprehension: A critical review. Language and Linguistics Compass, 4(10), 925-937.

[24] Traxler, M. J., Tooley, K. M., \& Pickering, M. J. (2014). Syntactic priming during sentence comprehension: Evidence for the lexical boost. Journal of Experimental Psychology: Learning, Memory, and Cognition, 40 (4), 905-918. doi: 10.1037/a0036377.

[25] Weber, K., Christiansen, M. H., Indefrey, P., \& Hagoorta, P. (2019). Primed from the start: Syntactic priming during the first days of language learning. Language Learning, 69 (1), 198-221. doi: 10.1111/lang.12327.

[26] Wolleb, A. (2015). Syntactic representations in the bilingual mind: The role of executive function and pragmatics in crosslanguage priming. PhD dissertation. The Arctic University of Norway, Center for Advanced Studies in Theoretical Linguistics (CASTL).

[27] Zawawi, A. (2017). Quantifying syntactic priming in oral production: A corpus-based investigation into dyadic interaction of L1-L1 and L2-L2 speakers of English. Lancaster University. doi:10.17635/lancaster/thesis/212.

[28] Ziegler, J. \& Snedeker, J. (2019). The use of syntax and information structure during language comprehension: Evidence from structural priming. Language, Cognition and Neuroscience, 34 (3), 365-384. doi: 10.1080/23273798.2018.1539757.

Reza Raissi is an assistant professor in TEFL in Islamic Azad University of Varamin, Pishva campus. He received his PhD in TESL from UTM University, Malaysia. His main area of interest is teaching methodology, testing and applied linguistics. Currently, he is teaching TEFL related courses for BA, MA and PhD students in several Iranian Universities.

Neda Hedayat is an assistant professor in linguistics at Islamic Azad University, Varamin-Pishva Branch. She has published several papers in national and international journals, and presented several conference papers regarding TEFL issues, linguistics and translation. Her main interest is applied linguistics, psycholinguistics, and quantitative and qualitative research. Currently, she is teaching several courses to BA., MA. and Ph.D. students at English Department of Islamic Azad University, Varamin-Pishva Branch. She has supervised several Ph.D. dissertations and Master theses.

Fakhereh Kazemirad is a PhD candidate in Teaching English as a Foreign Language at Islamic Azad University of VaraminPishva branch, Iran. She has been a university lecturer in Tehran, Iran since 2013, prior to which she has taught English at language institutions. 